\title{
The politics of data and reality in interdisciplinary social psychology
}

\author{
Chetan Sinha \\ OP Jindal Global University
}

\begin{abstract}
This article draws attention to the meaning of data and reality in social psychology, where everything is in the process, and one complements the other. Since social psychological data matters, data handling and interpretations in terms of cause-effect nexus, best descriptions and claiming of human subjectivities become a vital part of the advancement of social psychology. Social psychological enterprise is a political field where the role of structure and power give meaning to the data, and hence construct the reality. The current article discusses on the politics of data and power and how subjects of social psychology are not data in itself but active data processor. The observer perspective implied to understand others', if does not cater to the need of justice, the data is oppressive in itself.
\end{abstract}

Keyword: cause-effect, data, human nature, interdisciplinarity, reality, social psychology

In social psychological research, data are not context-free and asocial depictions but have cultural and emotional content in it which corresponds or reflects the world of people or animal (e.g. Qiu, Chan \& Chan, 2018). Data are interpreted and have perspectives and are societal reflections framed through the language of researchers. Data symbolise meaning which is of course not asocial and is laden in the institutional power dynamics (e.g. Ruppert, Isin \& Bigo, 2017). The differences in the ways of observations matters in the descriptions and the interpretations of the context. There were many cases when the forced and unsolicited linking to the theoretical frameworks, because the institutional metatheory goes by its assumptions, misses out the everyday experiences of the context. Some noted this mismatch due to the lack of appropriate language attributed to the everyday reality of people (see Shotter, 1994; see also Gerth \& Mills, 1953; Reicher \& Jogdand, 2017; see Howarth \& Andreouli, 2017). Since data of social psychological research does not have some pure language but its presence needs to be acquainted with the metaphors, which are usually not entertained in the typical disciplinary and Correspondence concerning this article should be addressed to Chetan Sinha, Ph.D., Jindal Global Law School, OP Jindal Global University, Sonipat, India-131001. Email: csinha@jgu.edu.in, sinchetan@gmail.com 
institutionalised structure leading to under-representation of the situations. The researcher regulated by the theoretical framework discusses the raw data and come to a particular conclusion and evidence. However, data is also prone to different kind of interpretations from what was intended, both from the eye of the community member and the researcher. The institutionalisation of theory has many times led to the faulty policy implications entirely distance from the need of the people from whom data in social psychological literature was obtained. The misnomers about the causation based on correlational evidence may be the subjectivity of the observer on the field since correlation does not only a matter of statistical appropriations, but it is the matter of the mind or subjective experience and social activity of the observer. To fetch what is in the mind of the observer is to be relying on some verbal and non-verbal cues attending to the phenomenon in hand. There is a large number of philosophical literature that turns to the language of the observers denoting the phenomenon (e.g. Hutto, 2008; Lakatos, 1978; Nagel, 1986; Popper, 1959). The question that "Why correlation cannot be causation or interpreted as causation, as it mostly happens in the sociolegal domains?" does not have a definitive answer. Since methodology in the social psychology, which can have the multiple roots to go into the basis of the phenomenon, is limited by the dominant trends of looking into the reality, and leading to the unnoticeable methodological dead ends, whose identification has become the necessary step for the intended social change during the data interpretations (see Parker, 1989, 2015). Interestingly, data comes out from the ground laden in the experiences and contexts, the barrel through which data are explored, assembled and interpreted cannot be claimed authoritatively to be the truth of the face. Truth changes its face as observed by the owner, which themselves have trespassed its own image into the continuous shifting identities.

\section{Data and reality}

The publicity of data in the disciplinary culture of social psychology has resulted in much uncertain formulation of theory based on something analysed in the published article but not into the critical consciousness of the people whose stereotypical and taken for granted actions the data showed. The illusion of findings masking the original raw data shown as something not needed to ponder upon. Since the researchers have already worked upon them and analysed data in terms of cause and effect and shown how they fit into the reality of the phenomenon under observation. The illusion had led to the supposition that reality is what shown to the community in terms of cause-effect nexus. However, the community is also part 
of that reality, but their reality gets modified with the researchers' ability to picture something which they had observed and manipulated. The concern here is not to debunk causation and believe in the randomness and coincidence (e.g. Owens, 1992; Harre \& Moghaddam, 2016), but to understand the causes which had been given the fixed meaning by the mainstream social psychology without cognisance to the causes which had mattered more than the described ones. For example, in his important work on banal nationalism, Billig (1995) posited that social psychological theories which based on the uncritical incorporation of social categories such as national identities, are missing something significant such as how people imagine their identity and how it constructs in an unnoticeable and banal manner that it is easy to forget. The taken for granted and seemingly formal aspects of everyday rationalities have been missed by the orthodox social-psychological frameworks (see also Smith \& Haslam, 2012). The socialpsychological frameworks created models claiming to have the predictive value for some phenomenon under observations, the idea of reality interpretations was universalised based on fixed sets of cause and effect. Causality is a matter of the importance given to things in a collective context where sharededness makes sense. Harre (2016) differentiated between causation and causality, as former is something which brings change to the present, and the latter is a description of this process of causation. Causation embedded in some series of causes structure defined in the narrow domain of any phenomenon which gives the certainty and meaning to the world. In scientific explorations, causes are searched and falsified. The location of the cause becomes a necessity to survive in the social world. In the case of disciplinary engagement with the cause, the way social psychology addresses the social meaning of any reality is a causally determined approach highlighting the nearest relationships among the variables concerned. In a multidisciplinary domain, finding the cause is a major task in hand, for example, the cause of the storm matters more than the actual storm itself, and then people engage in the precautionary or rehabilitation measures, connecting to the series of causes (Global warming, storm, consequences and measures). However, each determining event is picture in itself, and people are involved in various social and psychological events within them, which Harre (2016) pointed as 'conceptual essence' (p. 5). Taking this point to the metaphysics of life and death, life comprises a series of stories, it may be in the discretion of the storyteller to which area he/she focuses on describing the life history of the person, either at the vantage point of causes and events or simply the essence of whole life as good or bad. Consequences based on the collective activities, as seen through the social-psychological lens, are again the collective and shared form of sensemaking, which based on the networks of 
correlative connections. For example, our activities of voting and formation of any government by any party, are habitually seen as cause and effect, the majority of votes and winning of any political party. Here the group which identifies with that party is seen as rejoicing the effect as one of the results of their voting for their preferred party and those who didn't identify may offer other kinds of reason and not necessarily their voting as it didn't lead to the positive consequence. In the social world which social psychology captures, cause and action go together, and one nurtures the other. The typical handling of the causes or identification of it experimentally, give the models of cause-effect relationship but not necessarily acceptable to the diverse groups until the descriptions of the contexts cater to the phenomenon which matters to all the parties. The detection of the phenomenon (see also Haig, 2014) by the social psychologists are not the detection of the cause, as it showed through predictive analysis, but it's the construction of the cause with which the explanations attaches. If any monkey gets baffled by seeing itself in the mirror, how social psychologists figure out the cause of the monkey's excitement? Can we say the mirror is the cause or the monkey's observation of his corporeal being in the mirror is the cause? The fact can be the excitement of monkey or some other sample of its nature observed through the human development of the primate's social interaction model, but do the facts have a cause? If any bird every time hits the glass to eject out from the room despite a small hole in the room or another available thoroughfare, it injures itself and become exhausted or accept the situation. In similar lines, social psychology is not to creates custodians of causes and creates an illusion of available gateways as it happens in the case of birds trying to escape. Causes are meant to be debated and commuted through dialogues (see also Markova, 2003, 2016) but where is the right channel for debating and dialoguing causes is a matter of creating critical scholarship and authentic interdisciplinarity. This power dynamic is about the concretising of the causes linked to the power holders in the disciplinary domain. However, it doesn't mean that cause is not debatable since it is much institutionalised and taken for granted, but causes, when debated, creates an authentic platform for interdisciplinary social psychology.

Both data and reality may mislead if they are fitted continuously together through the vagaries of the fixed meaning of the features of any social construct under observation in social psychology. Metaphorically, as we see, there are different kinds of the surface with which we interact in the physical world, for example, the surface of the chair and the surface of the water. If the idea is to sit down, logically, the surface of the chair is factually suitable rather than the surface of the water. The manner social psychology connects the context with the facts, Correspondence concerning this article should be addressed to Chetan Sinha, Ph.D., Jindal Global Law School, OP Jindal Global University, Sonipat, India-131001. Email: csinha@jgu.edu.in, sinchetan@gmail.com 
sometimes rules of logic (see Harre, 1983, 1998) become overstated, as it happened in the case of social psychology where the ratified and reified understanding of the social categories like west or east taken for granted and given the absolute status (see Sinha, 2019). L. Wittgenstein in Tractatus showed that objective existence of the world is a fact and there is a universal language connected to those worldly facts, and later this view was further reformed to the human ability to play language games (Wittgenstein, 1958). There are rules for these games and rules are not the causes (see also Harre, 1998). About the reality, data picture it in the format driven by the rules of the theoretical framework, which gave impetus to the causes connected to some events. In the social world, the rules are not specified but based on the community norms, and so the causes are inferred accordingly. If social psychologists are interested in understanding the cause of any phenomenon, they derive certainty of methods from the stipulated norms of the discipline. The cause and the rules are not some objective facts, but the researcher task is to attain the proximity in causal relationships among variables under observation in social psychology. It is in the epistemological zone of the disciplinary activists who make sense of cause and effect. One example from social psychology can be the cause behind the interdependence among the low social class people is their need for social support, but then the cause can also be mediated by the role of cultural systems such as similarity in the language. So, there may not be anything like Aristotelian final cause, but the researchers of social psychology figure it out under the regulating domains of institutional culture.

The question is which methodological perspective suits the reality to come out with data reflecting its reality? The quantitative-qualitative quandary is not new, and much of the debate in social psychology was about the picturization of the reality in interest constructed through the personal and collective experiences and urge to show to the scientific community the evidence confirming their points. As reason given to identify for the cause may not lead to the ultimate cause, showing the limitations of reasoning which emerge in a set of notions about the cultural socialisation. Reasons can best be developed as per the cultural system allows (see also Simon, 1983) and the cause which catches the attention is a matter of reasoning. Science look for the cause which influences the phenomenon under observation validly and reliably, culture has many variants of noticing the cause.

There is quite a more connection between observable information from the perspective to understand the phenomenon. However, this is a picture like a shot taken at that moment, and 
there is a dearth of connection with the reality and the picture. The data collector may argue that at least this picture is a mark of some reality. However, some reality may be an angular projection of the spatial object. What does data show can reside in the belief system and prejudices of the data showers and sharers (see also Meyer, 2018) and with the new dominant trends of citations of articles having huge numbers is creating more sceptics as much as conformists.

What is data and how they catch reality? What is empirically valid data and what researchers do to check their claim through the data? In what way data programmed to establish its real nature? Can't it be questioned? Why not the observation and its narratives not sufficient? Our data always placed in some theoretical box or seen through the theoretical, cultural lens? There is a version of defiance of reality as too objective to be taken as truth. In the philosophy of psychology, data are evidence to support the arguments, and it has high propensity to be misused also. Now the misuse of data doesn't match up with the reality in a particular time and space, and reality has a geometrically infinite number of angles to be interpreted. So reality can also be constructed. However, the necessary facet of reality is there. For example, in the Indian context, the issue of justice is interpreted from the perspectives of people involved as victims and perpetrators. However, that doesn't stop there, as justice is the concept value loaded. Data is essential but may hijack one's cognitive system at both the individual and social level, if not contextualised within the broader theoretical essence of social sciences. We have an extensive account of data mismanagement which has not been through a simple replication exercise when reductively tested in the discrete and a contextual setting, not taking into account the broader cultural debates. The notion of cause and effect in its simplified form miss the conceptual makeup of any phenomenon under study. The status quo of knowledge production and practice are driven by the theoretical or ideological movement rather than data movement. It shows that data alone has limitation unless manipulated by the theoretical explanations in the unidirectional way. Thus, the theoretically charged arguments travel far and tend to cross the barriers of geographical and cultural boundaries (see Eacott, 2016).

Adding further to this, theoretically charged arguments crosses the social and group understanding in the case of social psychology. The data showing the exactness of the reality seems to be the turning point for social psychology if it confirms through the approaches of interdisciplinarity. The disciplinary movement in social psychology to search for the exactness 
and certainty of some phenomenon occurring in some context, created the boundaries of interpretations and the conditions implied were quite different from the conditions worked upon by other disciplines. It is not the problem of data constructions and interpretations since the boundary under which the situations are examined nurtured specific questions. Some of the scholars advised for the displaying of conditions of data constructions and analysis rather than blindfolded data only (Bourdieu \& Wacquant, 1992; Eacott, 2016).

\section{Claiming Human Nature through data}

Thony Christie ${ }^{1}$ recently in his article published in Aeon Magazine titled "Galileo's reputation is more hyperbole than truth" said that "Galileo was part of a collective, a whole community of brilliant thinkers who were expanding the boundaries of science" and not just the unique voice overhauling the whole rigid paradigm in Kuhnian sense. However, it was observed latter in the scientific history that Galileo was the primary spokesperson for the literal truth of the heliocentric theory, but the model he proposed was incorrect in comparison to the Kepler's observation that the orbits of the planets are elliptical (Zachar, 2014, p. 2). Also Weinberg (2001) pointed that "we have to be wary lest the great heroic ideas of the past weigh upon us and prevent us from seeing things in a fresh light, and it is just those ideas that were most successful of which we should be wariest (p. 118) (as cited in Zachar, 2014, p. 3). One of the contentions between social scientist pretending to be a natural scientist and natural scientists claiming to be an authority on the natural phenomenon is on the nature of truth under their realm of explorations. The mainstream social scientists like social psychologists pretend to be providing an authentic theory about human nature as compared with the critical social psychologists who questions the foundation of scientific claims. Scientifically social psychologists go by the available scientific methods which give them the power to authenticate their findings and replications reliably. On the other hand, critical social psychologists claim that their belief that the methods applied by the social psychologists are not grounded and most of the time come out with artificial findings not matching with the experiences of the stakeholders. However, from Latour (1987), it may be inferred that nature does not declare itself to be natural, but the communities of scientists declare its nature'. So all the theories connected to the phenomenon are dependent upon the availability of methods and techniques

\footnotetext{
${ }^{1}$ Galileo's reputation is more hyperbole than truth. In Aeon magazine. https://aeon.co/ideas/galileo-s-reputation-is-more-hyperbole-than-truth
} 
and thus, not ending controversies about the inherent nature of truth is the reality. For example, Indian social psychology constructed in the social structure of caste hierarchy which provides a contingent value to other social status symbols such as occupation, income, properties, wealth which in turn provides contingency to the social institutions such as marriage, relationships, neighbourhood space. The complexity of human nature embedded within the cultural context and demystifying its existence under the garb of essentialism and universality make the scope of social psychology a narrowed enterprise.

The question is how we can catch the human nature and claim it as a property of social psychology (e.g. Forgas, 2003). The emergence of different varieties of methods and techniques has made this task more structured and systematic. Social psychology is also on the verge of being more datafied as it deals with the human self (see Lupton, 2018). This datafied and digitalised society where every social, cultural, political, and bodily information's are preserved and manipulated make the job hard for social psychologists who questions the metatheoretical assumptions and designs of mainstream social psychology to claim the data about the human. The antithetical worldviews of subdisciplines such as critical social psychology, which nurture its interdisciplinarity through the meaningful engagement with the sociopolitical contexts such as social class, gender identity, languages, goes beyond the concretisation of data. Though any available data needed further analysis and critical discussion, and here preservation makes sense, but uncritical handling and manipulation of these data leads to sociopsychological capitalism (Wexler, 1983) which creates alienation, commodification and exploitation of people who are the victims of power and dominant social system. Wexler from the Marxist perspective of capital accumulation speculated decades back that "the current social role of conventional social psychology is to normalise and legitimise everyday cultural reification" (p. 80). Wexler (1983) at least was positive about the contradictions which may make the reified social categories less believable and polarised, the current datafication and dataism (see Dijk, 2014) repolarise and concretise the social categories which critical social psychology advances for the social change. The repolarisation may lead to the emergence of surveillance culture on the part of institutionalised social psychology leading to inadvertent rejection of the critical scholarship and hence contrary to the agenda of interdisciplinarity. The objective status given to data in social psychology led to construe about any human nature through its fixed meanings. As Ingold and Hallam (2014) posited that material artefacts such as technology are not fixed but open to a new meaning, the psychological artefacts are also not the same but move along with the physical world. Data and Correspondence concerning this article should be addressed to Chetan Sinha, Ph.D., Jindal Global Law School, OP Jindal Global University, Sonipat, India-131001. Email: csinha@jgu.edu.in, sinchetan@gmail.com 
its estrangement into dataism may give official meaning to the theory, a critical check is a necessity so that its critical meaning may not go redundant.

Claiming is about the ownership which shows the owners right over any property which he/she justifies as his/her own in some relational context such as market where one pays for any commodity. On the similar lines, the disciplinary divides and the sense of ownership of theories and data based on particular kind of scientific activities derive the sensemaking of being into something like their creation or earned something like scholarships. The data are usually seen as the property of the researcher and the institutions. Social psychological theories about human nature based on some theoretical explanation of data or evidence don't fix its constitutive meaning. Claiming for something is also a matter of rights where one party claim its right over some goods or intellectual property. However, this kind of rights morally grounded into the justice of being entitled to the property without any harm to others and without any intention of breaching the dignity of others. Here the owner is the rightful person who holds a dignified and meaningful association with the property. In the social-psychological domain, the claiming of something psychological creates a false belief of being the rightful owner of psychological properties. Since the rightful owners are the subjects ${ }^{2}$ whose subjectivities in their daily activities or enactments make them the rightful owner of their psychology, which may also critically connects to the concept of free will. As an observer with sophisticated methods and claiming the subjectivities, unless both data taker and data holder embrace the interpretations in commonality, cannot be an individual property of social psychology as an observer. Lupton (2018) holds that "human subjects are permeable and open to the material world rather than closed-off and contained" (p. 4) showing the possibility of "onto-epistemological dimensions of human-data assemblages and their relationship to bodies and selves" (p.1). This sophistication of data structuring, data surveillance and data vigilance portrays human as basically constant. However, how human considered as fixed objects and how their interaction can be quantified (see Dijck, 2014, 2013)?

Interestingly, this deterministic stance and reification of human agency (information about the body, habits, attitudes such as liberal or conservative, predilections, stereotypes, emotions, cultural belongingness and socio-cultural interaction pattern and relationships) is gradually creating an information about the self which reify it publicly, lead to internalization

\footnotetext{
${ }^{2}$ Here subjects are not who are victims of experimental deception and observers bias but the active person or participant who consciously live with his subjectivities and experiences Correspondence concerning this article should be addressed to Chetan Sinha, Ph.D., Jindal Global Law School, OP Jindal Global University, Sonipat, India-131001. Email: csinha@jgu.edu.in, sinchetan@gmail.com
} 
and offers a technological resistance to the change that happens, limiting the history into the illusions of legitimate facts. The emergence of technology and reified self in the digitalised world added a new dimension to capitalism and neoliberalism, which is very much susceptible to be manipulated by the powerful. In other words, this determinism of self through the datafication may link to the neoliberal governmentality (Sugarman, 2015) and a new kind of social anxieties where empathetic understanding and community feeling suppressed by the powerful owner of other less powerful identities. In the garb of objectification, data and information about the human being, the identities as posited to get neutralized with the technological advancements, the majoritarian view seems to overcome the minority and latter conform to the dominant and objectified view about themselves leading to new face of collective movement, may be influenced by the neoliberalism (see Bhatia \& Ravipriya, 2018).

Data are not a stagnant entity, and it is in the will of the researcher to question his stance and approach by continuous engagement with the data thing which is lived by the people. Berlin (1999) discussed on different varieties of empirical propositions and aptly asked a question in the context of cleverness "Is he clever even when he is asleep?" Indirectly this shows that concepts and categories are fluid and mobile, and this assumption of mobility assures us that social change is possible by revisiting the categories which we had concretised in the past. The art and science of social psychology conjecture on past behaviour and reify it based on sets of attributes. Extracting data from the context is like separating life from the body and bereft it from vitality. Datafication process in social psychology as an approach to claim the reality is masquerading of the historical processes unless space for rethinking, re-acting and critical questioning generated. As Lupton (2018) endorsed the apt argument of Ingold (2013) that "the only way one can really know things - that is, from the very inside of one's being is through a process of self-discovery. To know things, you have to grow into them, and let them grow in you, so that they become a part of who you are' (Ingold, 2013, P. 1). This shows how researchers, as a social and political being renounce their prejudices and try to become the actors of the subjects' experiences. The social-psychological domain where identities are objectified and considered as involuntary advocating social psychology as a science since consistency is one marker of scientific explorations.

The paradox of social psychology is that it is not a science in a strictly natural science way but claim to be science and thus claim the attributes which labelled on human social interaction patterns. Data of social psychology, when assumed to be fixed, the general idea 
about the fixed meaning of identity is also created. In the time of digitalisation of self, identities marked as permanent at the cost of its essence of being in the new state of becoming. When identities situated in the permanent status, the prejudices and stereotypes attain the permanent status, and the historically oppressed identities become the object of power and imposed rationalities (see also Ruppert et al., 2017). However, scholars also have the positive view about the datafication and digitalisation where new information integrates to the old ones and keeps the picture moving (e.g. Lupton, 2016. 2017; Michael \& Lupton, 2015; Tanweer, FioreGartland, \& Aragon, 2016).

\section{The Politics of evidence in social psychology}

The role of governing bodies and institutions which are considered as legitimate bodies have an essential role in shaping the structuring of data and evidence. Since evidence is the supporting artefacts to the assumption that one hold about some mundane object and phenomenon, it can either be taken as structured or as a fluid process. The evidences are derived out of data and data doesn't speak for themselves, as it is a matter of who schematize the data and load it with the interpretations (See also Taguchi, 2012). These interpretations, while filtering in and out of different perspectives, makes the evidence in social psyfchology pure and unquestionable (see also Sampson, 1991). The evidence is the normative entity which is structured on the agreed-upon principle, for example, if the person intended to lie about his being present at the crime spot, this may be contrary to the witnesses who saw him present. So, there are classes of data presented, where one form of data may be showing a spurious correlation and other a valid one depending upon the facts which cannot be changed. However, societal and institutional norms offer a more significant moderating effect (see also Castaneda, 1982). Another example can be in the context of caste or gender discrimination in India or racism, where the facts of one's embodiment (e.g. skin colour, bodily features or poverty) and belongingness used in the framing of evidence. Data may be showing that person belonging to the low SES or social class and accused of some crime, but this knowledge framed in the context of class stereotypes that person from the lower classes are susceptible to do the crime.

Data and evidence may be turned around also, in terms of new understanding, if the propositional logic framed in the context of awareness of these stereotypes as a result of movements and protests. Data are also made animated by objectifying people from the 
oppressed community as a statistical number who doesn't have a voice or critical stance. It is all in the discretion of the dominant researcher to label people with their theory. When oppressed people become the object of datafication, data also become oppressive. The politics of data and evidence in social psychology can't be neutral in the name of statistical limits as there are the chances of error and unlike a mathematical algorithm which shows a defined solution, it's conjecture has been refuted or led to the replication crisis (e.g. Klein, 2014; Hubbard \& Lindsay, 2008; Świątkowski \& Dompnier, 2017; see also Trafimow \& Earp, 2016). The faulty and forced alignment with the set of causes without respecting the meaning and qualitative picture of the context can also be the case for the chaos and anxiety in the socialpsychological domain for replicability. Since data and evidence also somewhere embark on justice and rights, causes and correlations have to be dealt with carefully. Bogen and Woodward $(1988,2011)$ theorised and philosophically approached the problem of how any phenomenon can be accurately connected to the data and hence the evidence (see also Haig, 2014; Rohrer, 2018). Detailed knowledge about being in some state of mind is a matter of linguistic positioning and interpretative turns that counts on the authenticity of the data and evidence. The evidence is not neutral though sometimes with the influence of power, it becomes taken for granted. It points out that it is in the scientific realm to deduce from the phenomenon or make generalisation through induction or forming the best possible explanation of the observation through the abduction (Haig, 2014). It argues that in the scientific domain, nothing is beyond these theories of the method.

However, science is not acontextual, and all the interpretations are the matter of the language of science under which cause-effect and descriptions are constructed (see also Hacking, 1990). In the case of social psychology, data interpreted in the above-mentioned criteria of methodologies. The reality of the context is a matter of identification and interpretation of the context which is an essential aspect of social-psychological politics, whether it is pro-social justice and change (e.g. Penic, Elcheroth \& Reicher, 2016; Reicher et al., 2006; Tajfel \& Turner, 1979; Reicher \& Jogdand, 2016; Tajfel, 1969) or deterministic and in favour of established structure. Research in social psychology is not something where the researcher is seated on the backseat and looking the play of reality and acting out, but researcher enacts the data, construct the data and define the situation through the series of activities and sophisticated languages. Facts are engaged to form of sociality where the social worlds create a conglomeration of ideas and activities (see Berger \& Luckman, 1967; Gergen, 1992; see also Searle, 1995, 2009). The politics for the empowerment of the oppressed and the politics of Correspondence concerning this article should be addressed to Chetan Sinha, Ph.D., Jindal Global Law School, OP Jindal Global University, Sonipat, India-131001. Email: csinha@jgu.edu.in, sinchetan@gmail.com 
suppression of the oppressed move through different forms of activities. The socialpsychological politics where data and evidence are for collective movements and emancipation of the oppressed (e.g. Baro, 1994; see also Baxi, 2000), this politics for power sharing may contribute authentically to the interdisciplinary social psychology. The politics which go against the need of oppressed and dehumanise them as aloof numbers go antithetically to the agenda of social psychology to understand the social world in the actions and thinking of people in a social context. Data that liberate from the shackles of power and shows the reality of power can be considered valid for social psychology.

Ruppert et al (2017) raised the issues of data being constituted 'as an object vested with certain powers, influence, and rationalities" (p. 1). They questioned the creation of data as an object of power and its role as an object of knowledge. The concern is how social psychological enterprise takes cognizant of the power dynamics in the objectification of data and evidence and how it critically handles these issues. Even if the replication crisis is resolved the power dynamics to handle the social context and reproducibility of pieces of evidence are a matter of reflexive questioning and beyond. There is evidence about the politics of data where power and institutionalisation of epistemology shape the sensemaking of data, unlike critical social psychology where data questioned from the context of a social movement, power-sharing and oppressive social structure. The differences in perspectives to reach the truth about human nature in mainstream social psychology was evidence or data-based. However, some of the new viewpoints questioned the authenticity of the data in terms of lack of representation to the population directed at and exaggerations of inferences out of it. The notion of being scientific is not limited to the singular way of observation, but it is the process of raising critical points in the available theories and looking into other aspects of the phenomenon. The dominant approach of knowing or inferring about the causes behind human actions have been the most preferred in social psychology, and it assumes that the human thinks in terms of causality (see Asendorph, 2012; Rohrer, 2018; see also Haslam \& Mcgarty, 2004) and there is always a source of influence present either externally, internally, or both. For example, some of the studies looked into the sources of causality in the social-psychological phenomenon (e.g. Heider, 1944; Bandura, 1985; Hirschfeld, 1996; Kronenfeld, 2014; Sussman \& Gifford, 2018). However, this interdisciplinary approach towards the understanding of any phenomenon in question is not without limitations. For example, Joseph Needham taking the context of the invention of gunpowder highlighted its merits and demerits and pointed towards the unfortunate aspect of history to only come out with its disastrous picture (cf. Needham, 1986). 
Scientific understanding is laden within the context of the context and inferring based on a singular meaning of the data is an incomplete picture. The current disciplinary discourses seem to follows the pessimistic inductivism, with the assumption that all theories are fallible like all other previous scientific theories. It is right in the context of Popperian logic, and it has its relevance in understanding the phenomenon carefully through falsificationism. One of the benefits of these kinds of exploration is that it relies on the steps common to most of the scientific enterprises and based on the observations and reactions. The problem with these exact steps is rigidity for modification or the respect for the interdisciplinary approach.

\section{How does the data matters?}

Data is collected, and the impression made about the phenomenon. Manipulations and deception may not account for the correct understanding of the everyday experience of people, what makes sense are the description and the way people make sense out of their life. The task of the researcher is to find this out through the descriptions embedded in the actions, social engagements and talks, both verbal and non-verbal. Manipulation through experimental methods may lead to fallacies without much space for the congruent policy implications. One of the observations about the daily activities of children, for example, playing merry go round does not reveal much in itself unless the children are drawn towards it and make it go round, which we call as playing and the situation of playing as an amusement. The very primary debate about the construction of the situation as amusement is our collective subjective understanding of the quality of good feeling spread in our memories and experiences. This observation of an instance and its interpretations may also compose as a kind of belief about the play, but here in no way, we see manipulations but simple observations and interpretations. The quality of evidence which pertains to play, for example, usually links to some because which may have lead children to play. Here the merry go round system may then be the cause leading to the play and further leading to the situation of amusement. If any social psychologist, interested in knowing the amusement of children, do the manipulations of play behaviour by bringing children as subject to the playing ground, showing varieties of playing instruments and judging based on the children preference and playing, his methodology shows the descriptions and norms rather than the amusement. Data in itself doesn't conjecture reality as some reality conjecture the datum, as in the case of playing, we are in no way sure from where the amusement surfaced. The very instance of the children excitement by seeing the playing instrument can best model as playing behaviour and the emergence of amusement. So here the 
reality of amusement, as interpreted by the social psychologists, doesn't correspond to any cause-effect system but the situations which described in the actions of children involved. This action is only worthy of descriptions rather than putting it into the category of cause as a determiner of the amusement felt, in other words, interpreted by the social psychologist. The social psychologists' interpretations are not the knowledge which he/she holds but his/her whole position as an observer and as the narrator of the event and as a participant. The best way to fall into the intricacies of cause and effect, as for social psychologists, is to make something real because his observations and reliability of his methodology pertain to it. The data and its connections to the series of actions and events are not simple or in other words, deserves the criticisms of the actors who observe and interpret. In one sense, amusement is not the consequence, as seen among the social psychologists, but has its holistic meaning flourishing in the context of playing. The labelling and bracketing of the contexts of new actions can be evidence-laden in the description of the context and meaning.

In certain other situations, for example, the routinization of the mind in contexts like organisation, where one has to adapt to its institutional culture. The brain scientists may fall into misperceptions between the determinism of brain and freedom of will of the employee. If the employee needs to adapt to the routine of the organisation, he/she has to control his/her brain to avoid unnecessary neural firings which may deviate the employee from the disciplined actions, for example, regularity and punctual behaviour. We have several living examples where the external notions of times matched by regulating the biological time. The paradox underlying in this kind of cases is a straightaway critique of the stiffness of determinism and scientific demeanour of brain science. So, here, the interpretations and enactment of the will, defy the naturalness of the brain. However, the circumstances are not the same, and the brain is reported to have the neural firings despite all the external control through the clocked culture. It may be a springboard to understand further that cause may be elusive since it may not fit, at least in the social sciences like social psychology, where its uneven nature may be giving some contrary observations to the scientific realism, where cause and effect don't fall into the reliable frameworks. Some of the other patterns of seeing the context has been discussed widely by the social psychologists (e.g. Billig, 1991; Augoustinos, Walker, \& Donaghue, 2014) where contexts are just not the regulators or cause of people actions but instead people with their action, thinking activities and free will, design their everyday reality. The scope of this kind of research again is not at all about the causes as believed by the social psychologists but the hermeneutic turn that the researchers and respondents co-construct in some cultural space. In 
one way, the phenomenological approaches to dwelling into the folk psychology of the actors' engagement with their social environment, is a description of their consciousness from the actors-researchers' perspective. The concern here is about the range of interdisciplinarity which has either legitimised the causes or gave the overview of the contexts and interpretations on the sequestered meta-theoretical avenues. The historical conflict between two nations and showing of the political will of one nation to make the military attack on the other nation are all the linguistic twists opted by the dominant regime and the media together. So, the first part is the interpretations and maybe data for further interpretations, but nowhere it shows the cause.

The collective intentionality of the nations and the political tussle in the attacking nation constructed the language of political will showed by few. The way interpretation of data happens possibly makes it legitimate or illegitimate rather than the data in itself. The most comfortable zone of the experimental social psychology is the deception of the premise in question and indirectly to infer a cause for some expected situation through the manipulations. Manipulation and deception as the critical features of the experimental social psychology develop its identity under the zone of replications and validations (see Borsboom, 2004, 2005; Michell, 2001, 2004), discounting the description as lower on the research hierarchy of social psychology. The emerging domains of social psychology are not into the searching of fact through the manipulations of human behaviour, typically considered as authentic and scientifically sophisticated, which is debatable. The argument here is not discount the methods used by the social psychologists but to the dominance of methods which sustained its identity. Social psychology is one of the potential right hand of the critical social science which emerged as one of the eye-openers to the social issues from the psychological perspectives. In one-way social psychology is a science, where it has the potential to be reliable, uniform and replicable, and these criteria confirmed through the divergent perspectives of social sciences. The essence which the serious social psychologist provides corresponds to the reality of the people who have worked upon the sensemaking of issues like social justice and human relations. The data in social psychology, observed through different circumstances, are the understanding of the context with the history of occurrence in the past as embedded in the knowledge of the people for whom the context mattered. The meaning of any data, which is derived through the sets of responses, and seems to be fitting into the rules of logic conveying the reality of any group under observation, may also get the shift of understanding through different perspectives of the observers and the observed. How can these statements be genuinely assessed and judged? The basic rule to understand the context of social psychological knows how it is to have Correspondence concerning this article should be addressed to Chetan Sinha, Ph.D., Jindal Global Law School, OP Jindal Global University, Sonipat, India-131001. Email: csinha@jgu.edu.in, sinchetan@gmail.com 
corroborative tools to come to surety about the interpretations which the researchers have made. However, those rules of research and data observations are normative sensemaking, where rules do not say anything in itself (see Wittgenstein, 1958).

The method of locating or interpreting something as data conjectured based on relational rules appropriated by the research community and institutional metatheory (see also Sinha, 2019). In the social psychology or the other dominant fields of psychology, whose metatheory gets fuel from its methodological juggernaut, the cause-effect doesn't seem perspicuously present either in the enactment or in the sensemaking process (see Drury, 1976; Weick et al., 2005). The platform which supports the standing of social psychology as manipulations of cause and effect is the base created in the Zeitgeist, to create the disciplinary hallmark, rather than giving a qualifying account for any reality emergence. Since social psychology seems to be the little master of social science family, it has the nature to deal with any phenomenon understanding in terms of cause and effect and reducing it into a set of miniature models. The question is about the authentic association between the norms of social science and how social psychology abide it, as social psychology's contribution to the interdisciplinarity literature is also but sets of conjectures offered to some problems which may have more significant interpretations too.

One proposition that may stick to the current arguments is that interdisciplinarity doesn't stop where social psychology stops and so the vice versa. Interdisciplinarity is a change program leading out the disciplines in silos (see Jacobs, 2013) from the shackles of misunderstanding and tightened, departmentally constrained disciplinary boundaries. One speculation can be about the interdisciplinary turn for social psychology is its methodological sophistication that bounces on the final argument making the argument legitimate. Though several studies in recent times call for the replicability and the emergence of replication crisis where prediction fails to acknowledge the context as it was interpreted in the earlier studies (see Klein, 2014). One of the major points here is about the blind reliance on something as cause or series of causes regulating and predicting the effect. This uncritical reliance on the cause and effect and taking it as the social-psychological underpinning of human social relationship is in itself lacking the acknowledgement of something which does not operate in cut to cut manner but holistically and completely. There are presupposed features in social psychology which are uncritically took for granted and utilised in conjecturing the questions of interest. Though these presupposed features may have a wide range of understanding in the 
other disciplines of social sciences and sciences, their use in the language of social psychology may give meaning susceptible to be reliable and universally applicable. Then in what way we can have a critical sense of it? Do they in itself denote the features of our reality which social psychology is interested in figuring out? If reality is questioned, why not its lens and enactments through which any reality gets constructed? It is no surprise that the rejection and acceptance of this lens go simultaneously in front of us, and its banality is unnoticed. The world and society are not about the legitimised causes and effects which social psychologists try to mirror or make the visible, again visible, but the totality of experiences making its presence objectified as the researcher's knowledge. This knowledge as embedded in the researcher's acts of observations is something about his pillaring of the data under the garb of some established theories, a connection of cause and effects to explain the meta-realities of any phenomenon, which was descriptions of some events leading to the emergence of situations of researcher's interest. The psychology of social and social contexts reduced to the mechanism of data fitting into some form of preconceptions, which departs the researcher from the accurate description under the garb of cause-effect nexus ${ }^{3}$. The preconceptions and illusions about the speculative realism overshadow or bleak the visibility of those objects which must be given the primary attention ${ }^{4}$. This overshadowing of the cultural objects in the dominant social psychology, allowed the gravest situation to emerge, though it embraced by the social psychologists manoeuvring with the criticality and authentic interdisciplinarity (e.g. Prilleltensky, 1994; Pancer, 1997). One of the examples is about the rising soft fascism in India, for instance, which observed through several instances of violence towards the minorities. The description of these observations may be the authentic interdisciplinarity which may help minorities at the level of policy-making and protections. However, there are some other factions of a researcher, who deny this fact and label this violence as the aftereffect of historical violence happened over the Hindus in the mediaeval period. We can see the first instance is about the history of violence based on the observable facts in the present and the second interpretations as going into the mythology of some short-sighted past and putting everything in the cause and effect relationships. Wittgenstein (1958) rejected something philosophical laden in cause-effect and tautologies and aptly stated that "we must do away with all

\footnotetext{
${ }^{3}$ Drury, M. (1976). The danger of words and writings on Wittgenstein. Bristol: Thoemmes Press. An important quote of Wittgenstein about the cause-effect nexus- "Belief in the causal nexus is superstition"

${ }^{4}$ William James (1958). Varieties of religious experience. New York: A Mentor Book Correspondence concerning this article should be addressed to Chetan Sinha, Ph.D., Jindal Global Law School, OP Jindal Global University, Sonipat, India-131001. Email: csinha@jgu.edu.in, sinchetan@gmail.com
} 
explanation, and description alone must take its place. And this description gets its light, that is to say, its purpose, from the philosophical problems" (PI, 109). Social psychological theorisations are not beyond our everyday interaction, whether one speaks or not. The socialpsychological problems are philosophical too, which emerge from the grounds around us. Knowing is to become conscious. The concern here about the dominant social-psychological stances are about the consciousness of the pro-powerful identity questions (e.g. problems of migration, minorities taking over the job, stopping the social mobility and change of dominant groups), which need to be rejected from the consciousness by the critical social psychology, authentic interdisciplinarity and social actions for social justice. About this, Wittgenstein, in the same section (PI, 109) stated that "The problems are solved, not by giving new information, but by arranging what we have always known".

\section{The future of evidence in social psychology}

Social psychology assumes that behaviour varies and so there are chances of error, due to uncertainties attached to the differences in the cultural systems and values which is difficult to understand in its complete forms (see Kantor, 1923), as it assumes that the reality of human is both brain-mind dependent (e.g. Flangan, 1991) or socially (e.g. Kadianaki \& Gillespie, 2015) and discursively embedded (Harre, 1993; Shotter, 1994). It is not like some physical phenomenon where their occurrence is predictable like some universal truth, though, variations and new shreds of scientific evidence obtained in the realm of physical phenomenon have the potential to be falsified (Popper, 1959). In the context of the social-psychological phenomenon, we obtain result about the cause immediate to our prediction (see White, 1990; 1993). So, what does this immediate or approximate proximity means in the social-psychological facets and why its occurrence depends on the chance factor? What is the meaning of evidence? Why evidence matters and how evidence are collected to create its authentic picture? Social psychology has a big picture and unending future where it may offer a realistic critical account of the phenomenon with its propensity to be interdisciplinary. Are evidence stagnant, or it is a continuum and what its connection with the memory and subjectivity? Whether social psychology is interdisciplinary or not is a matter of perception, and that too depends upon the platform on which we are standing. Natural scientists may think about social psychology as an essential subject to study about social behaviour, and they may look for the underlying mechanism which regulates the human social behaviour, though differences recorded among the different disciplines. The research which is not able to connect and engage with the 
everyday life of people generates spurious data leading to a dangerous conclusion. Some of the recent retracted and questionable research in social psychology and allied disciplines raised the debate on the meaning and authenticity of the data and model fit (see Crocker, 2011; Verfaellie \& McGwin, 20115). However, social psychological researches produced many classic experimental studies (e.g. Devine \& Brodish, 2003) addressing to the human nature and the social context having 'served common points of references for researchers, teachers and students' (see Smith \& Haslam, 2012) which were well known outside the discipline providing concrete understanding about the human nature and the social context (Moscovici, 1984; from Smith \& Haslam, 2012). These social psychological studies tested the time and the differences in the statistical variances during the replication can be attributed to the sociopolitical situations and human sensemaking with the complexity of the contexts and the revisiting of the data. As per the changing times and emergence of a new form of cultural perception such as neoliberalism and individualising of the society, there were many contrary viewpoints to the social psychological research.

Are we limited to the set pattern of assessment and method or there is a room for intuition, or all the methodological stance are intuitive only to arrive at one's preconceived arguments? Paradigms dominate methodological space (whether quantitative or qualitative) seems to be suited to do research for different concepts and fall into discomfort zone where the true self of the researcher overpowered by researchers' stance due to training in methods. Researchers observations and subjectivities impact the direction of research. The researchers' exploration of different communities' act both ways, as a neutral observer or as a healer who helps members to open up and speak about their experiences. It may not be necessary that only one way of seeing or collecting the field impressions (e.g. through the authentic ethnography) is the valid method but direct interaction between members and the researchers where researcher know and communicate that he/she is from different community and wish to know the culture of the group or community. In a real sense, no methodology (e.g. doing ethnography) can claim of picturizing the everyday reality of the group, though it comes out with thick descriptive data. How one may claim to be understanding the mind of the individual or group mind as being from another group, culture and socialisation history. The process of these kinds of methodological adventure may help in understanding, but it still not captures true subjective intricacies. There is evidence when the proposed hypothesis and its testing through the

\footnotetext{
5 The case of Diederik Staple Correspondence concerning this article should be addressed to Chetan Sinha, Ph.D., Jindal Global Law School, OP Jindal Global University, Sonipat, India-131001. Email: csinha@jgu.edu.in, sinchetan@gmail.com
} 
traditional methodological practices devalued the relevance of the research questions intended to be explored, leading to the uncertain and premature outcomes and insufficient generalisation. The mainstream occult of methodological legitimacy disturbs the researchers' identity (see Harvey, 2013 ${ }^{6}$ ) and the filed experiences depriving the research of the real ontological and epistemological spirits. In social psychological researcher, researcher identity of being mainstream researcher coming, for example, positivistic background, however, may prove to be dangerous, as researcher try to forcibly limit himself in the paradigm and mood of positivism and quantification, intentionally avoiding his pure naturalistic gut to conclude. The experiences in the field and how they are not the same due to alienating features like languages, caste, class, gender and religion, and yet how they unify the common understanding. In some cases of time, this alienation contributes more to understanding than the available knowledge. Further, the questions like, the knowledge from whose perspective? What is the mechanism of privilege? Is knowledge different for power than it is for oppressed (Parker, 2005)? The need is to understand through the methods of liberation and anti-power perspectives. The concept of biasedness and unbiasedness in the research may need a revisit. The opening up of the room for the future researches is to come out of the scepticism towards the previous researches claiming to be unbiased and in this way advances, understanding advances. To be unbiased and giving a universal picture of any phenomenon is boorish and self-acclaiming and uncritical. Do some concepts and their relationship convey the natural flow of relationship? Some social psychological concepts explored in a set pattern of methodological style giving limited space to innovative and creative findings. The researchers in psychology trying to understand the related concepts very much pertains to his experiences and the biasedness towards the persons experiences is actually more informative and meaning constructing in comparison to the emptiness to be unbiased and giving a grim picture of universalities denying the role if identity, social context, political makeup and room for future explorations. For example, how evidence of social psychology needs to be looked at carefully? Why social psychology matters and its merging with some of the sub-disciplines like neuroscience is absurd to act, in a similar way when we mix any colour with black, the outcome retains the essence of black. Some of the interdisciplinary connection, unless the metatheory is seen critically, (e.g. in the case of the marriage of social psychology with the neuroscience) (see Dovidio, Pearson \& Orr, 2008) may

\footnotetext{
${ }^{6}$ Jonathan Harvey (2013). Footprints in the field: researcher identity in social research Correspondence concerning this article should be addressed to Chetan Sinha, Ph.D., Jindal Global Law School, OP Jindal Global University, Sonipat, India-131001. Email: csinha@jgu.edu.in, sinchetan@gmail.com
} 
be a dangerous friend in the future of social psychology unless its structure and metatheories rehabilitated.

\section{References}

Asendorpf, J. B. (2012). Bias due to controlling a collider: A potentially important issues for personality research. European Journal of Personality, 26, 391-392.

Augoustinos, M., Walker, I., \& Donaghue, N. (2014). Social cognition: An integrated introduction. New Delhi: Sage.

Bandura A. (1985) Model of Causality in Social Learning Theory. In: Mahoney M.J., Freeman A. (Eds.), Cognition and Psychotherapy. Springer, Boston, MA.

Baro, M. (1994). Writings for a liberation psychology. Cambridge: Harvard University Press.

Baxi, U. (2000). Emancipation as justice: Legacy and vision of Dr. Ambedkar. In K. C. Yadav (Ed.), From periphery to centre stage: Ambedkar, Ambedkarism and Dalit Future (pp. 49-74). Delhi: Manohar.

Berger, P. L., \& Luckmann, T. (1967). The social construction of reality: A treatise in the sociology of knowledge. New York: Anchor Books.

Berlin, I. (1999). Empirical propositions and hypothetical statements. In H. Hardy (Ed.), Concept and categories: Philosophical essays (pp. 32-55). London: Pimlico.

Bhatia, S., \& Priya, K. R. (2018). Decolonizing culture: Euro-American psychology and the shaping of neoliberal selves in India. Theory \& Psychology, 28 (5), 645-668.

Billig, M. (1991). Ideology, rhetoric and opinions. London: Sage.

Billig, M. (1995). Banal nationalism. New Delhi: Sage

Bogen, J., \& Woodward, J. (1988). Saving the phenomena. The Philosophical Review, 97(3), 303-352.

Borsboom, D. (2004). The concept of validity. Psychological Review, 111, 1061-1071.

Borsboom, D. (2005). Measuring the mind: Conceptual issues in contemporary psychometrics. Cambridge: Cambridge University Press.

Bourdieu, P., \& Wacquant, L. (1992). An Invitation to Reflexive Sociology. Chicago: University of Chicago Press.

Castaneda, H. N. (1982). Thinking and doing: The philosophical foundations of institutions. London: D. Reidel Publishing Company.

Correspondence concerning this article should be addressed to Chetan Sinha, Ph.D., Jindal Global Law School, OP Jindal Global University, Sonipat, India-131001. Email: csinha@jgu.edu.in, sinchetan@gmail.com 
Crocker, J. (2011). The road to fraud starts with a single step. Nature, 479 (7372), 151.

Devine, P., \& Brodish, A. (2003). Modern Classics in Social Psychology. Psychological Inquiry, 14(3/4), 196-202. Retrieved January 24, 2020, from www.jstor.org/stable/1449675

Dijck, J. V. (2014). Datafication, dataism and dataveillance: Big Data between scientific paradigm and ideology. Surveillance \& Society, 12(2), 197-208.

Dovidio, J. F., Pearson, A. R., \& Orr, P. T. (2008). Social psychology and neuroscience: Strange bedfellows or a healthy marriage? Group Processes \& Intergroup Relations, $11(2), 247-263$.

Drury, M. (1976). The danger of words and writings on Wittgenstein. Bristol: Thoemmes Press.

Eacott, S. (2016). Mobilizing Bourdieu to think anew about educational leadership research. In M . Murphy \& C. Costa (Eds.), Theory as method in research: On Bourdieu, social theory and education (pp. 101-114). London and New York: Routledge

Flanagan, O. (1991). The science of mind. Cambridge: The MIT Press.

Forgas, J. (2003). Why Don't We Do It in the Road...? Stereotyping and Prejudice in Mundane Situations. Psychological Inquiry, 14(3/4), 251-257. Retrieved January 23, 2020, from www.jstor.org/stable/1449684

Gergen, K. J. (1992). Social psychology and the phoenix of unreality. In S. Koch \& D. E. Leary (Eds.), A century of psychology as science (pp 558-590). Washington, Dc: American Psychological Association.

Gerth, H. H., \& Mills, C. W. (1953). Character and social structure: The psychology of social institutions. London: Routledge \& Kagan Paul

Hacking, I. (1990). The taming of chance. UK: Cambridge University Press.

Haig, B. D. (2014). Investigating the psychological world: Scientific method in the behavioural sciences. Cambridge: The MIT Press.

Harre, R. (1983). An Introduction to the Logic of the Sciences. London: The Macmillan Press Ltd.

Harre, R. (1993). Social being. Oxford UK: Blackwell.

Harre, R. (1998). The epistemology of social representations. In U. Flick (Ed.), The psychology of the social (pp. 129-137). Cambridge: Cambridge University Press. 
Harre, R. (2016). The discourse frame. In R. Harre \& F. M. Moghaddam (Eds.), Questioning Causality: Scientific explorations of cause and consequences across social contexts (pp 3-20). Denver: Praeger

Harre, R., \& Moghaddam, F. M. (2016). Questioning Causality: Scientific explorations of cause and consequences across social contexts. Denver: Praeger.

Harvey, J. (2013). Footprints in the Field: Researcher Identity in Social Research. Methodological Innovations Online, 8(1), 86-98.

Haslam, S. A., \& McGarty, C. (2004). Experimental design and causality in social psychology research. The SAGE handbook of methods in social psychology. UK: Sage.

Heider, F. (1944). Social perception and phenomenal causality. Psychological Review, 51(6), 358-374.

Hirschfeld, L. A. (1996). Learning, development, and conceptual change. Race in the making: Cognition, culture, and the child's construction of human kinds. Cambridge, MA, US: The MIT Press

Howarth, C., \& Andreouli, E. (2017) (Eds.). The social psychology of everyday politics. Oxon: Routledge.

Hubbard, R., \& Lindsay, R. M. (2008). Why P Values Are Not a Useful Measure of Evidence in Statistical Significance Testing. Theory \& Psychology, 18(1), 69-88.

Hutto, D. D. (2008). Lessons from Wittgenstein: Elucidating folk psychology. New Idea in Psychology, 27 (2), 197-212.

Ingold, T. (2013). Making: Anthropology, Archaeology, Art and Architecture. London: Routledge.

Ingold, T., \& Hallam, E. (2014). Making and growing: An introduction. In T. Ingold \& and E. Hallam (Eds.), Making and Growing: Anthropological Studies of Organisms and Artefacts (pp. 1-24). London: Routledge.

Jacobs, J.A. (2013). In defense of disciplines: Interdisciplinarity and specialization in the research university. Chicago and London: The University of Chicago Press.

Kadianaki, I., \& Gillespie, A. (2015). Alterity and the transformation of social representations: a sociocultural account. Integrative Psychological and Behavioural Sciences, 49 (1), 73-88.

Kantor, J. R. (1923). What are the data and problems of Social Psychology? Journal of Philosophy, 449-457. 
Klein, S. B. (2014). What can recent replication failures tell us about the theoretical commitments of psychology? Theory \& Psychology, 24(3), 326-338.

Kronenfeld, D. B. (2014). What "causal cognition" might mean. Frontiers in psychology, 5, 1204. doi:10.3389/fpsyg.2014.01204.

Lakatos, I. (1978). The Methodology of Scientific Research Programmes, Cambridge: Cambridge University Press.

Latour, B. (1987). Science in action: how to follow scientists and engineers through society. Cambridge, Massachusetts: Harvard University Press.

Lupton D (2016). The Quantified Self: A Sociology of Self-Tracking. Cambridge: Polity Press.

Lupton D (2017). Feeling your data: Touch and making sense of personal digital data. New Media \& Society 19,1599-1614.

Lupton, D. (2018). How do data come to matter? Living and becoming with personal data. Big Data \& Society. https://doi.org/10.1177/2053951718786314.

Markova, I. (2003). Dialogicality and social representations: The dynamics of mind. Cambridge: Cambridge University Press.

Markova, I. (2016). The dialogical mind: Common sense and ethics. Cambridge: Cambridge University Press.

Meyer, M. N. (2018). Practical tips for ethical data sharing. Advances in methods and practices in psychological science. 1 (1), 131-144.

Michael, M., \& Lupton, D. (2016). Toward a manifesto for the 'public understanding of big data'. Public Understanding of Science, 25, 104-116.

Michell, J. (2001). Measurement theory: history and philosophy. In N. J. Smelser and P. B. Baltes (Eds.), International encyclopedia of the social and Behavioural Science. Elsevier Science.

Michell, J. (2004). Measurement in psychology: A critical history of methodological concept. Cambridge: Cambridge University Press.

Moscovici, S. The myth of the lonely paradigm: A rejoinder. Social Research, 51, 939-967.

Nagel, T. (1986). The View from nowhere. New York, NY: Oxford University Press.

Needham, J. (1986). Science and Civilization in China. Volume 5. Chemistry and Chemical Technology; part 7, Military Technology: The Gunpowder Epic. Assisted by Ho Ping-yü et al. New York: Cambridge University Press.

Owens, D. J. (1992). Causes and coincidences. New York: Cambridge University Press. 
Pancer, S. M. (1997). Social Psychology: The crisis continues. In D. Fox \& I. Prilleltensky (Eds.), Critical Psychology: An introduction (pp. 150-165). London: Sage.

Parker, I (2015). Handbook of critical psychology. London and New York: Routledge.

Parker, I. (1989). Critical psychology series. The crisis in modern social psychology-and how to end it. Florence: Routledge.

Paul teller. (2010). "Saving the phenomena" today. Philosophy of Science, 5, 815-826.

Penic, S., Elcheroth, G., \& Reicher, S. (2016). Can patriots be critical after a nationalist war? The struggle between recognition and marginalization of dissenting voices. Political Psychology, 37 (4), 481-496.

Popper, K. R. (1959). The Logic of Scientific Discovery. New York: Basic Books.

Prilleltensky, I. (1994). The morals and politics of psychology. Albany: State University of New York Press.

Qiu, L., Chan, S. H. M., \& Chan, D. (2018). Big data in social and psychological science: theoretical and methodological issues. Journal of Computer Science, 1, 59-66.

Reicher, S., \& Jogdand, Y. (2017). Identity, emotion and mobilisation. In C. Howarth \& E. Andreouli (Eds.), The social psychology of everyday politics (pp. 102-115). Oxon: Routledge.

Reicher, S., Cassidy, C., Wolpert, I., Hopkins., \& Levine, M. (2006). Saving Bulgaria’s Jews: An analysis of social identity and the mobilisation of social solidarity. European Journal of Social Psychology, 36, 49-72.

Rohrer, J. M. (2018). Thinking clearly about correlations and causation: Graphical causal models for observational data. Advances in Methods and Practices in Psychological Science, 1(1), 27-42.

Ruppert, E., Isin, E., \& Bigo, D. (2017). Data politics. Big Data \& Society, 4 (2), https://doi.org/10.1177/2053951717717749

Sadowski, J. (2019). When data is capital: Datafication, accumulation, and extraction. Big Data \& Society. https://doi.org/10.1177/2053951718820549917.

Sampson, E. E. (1991). Social worlds-personal lives: An introduction to social psychology. San Diego: HBJ

Searle, J. (1995). The construction of social reality. New York: The Free Press.

Searle, J. (2009). Making the social world: The structure of human civilization. New Delhi: Oxford University Press 
Shotter, J. (1994). Conversational realities: Constructing life through languages. New Delhi: Sage.

Simon, H. (1983). Reason in human affairs. Stanford: Stanford University Press.

Sinha, C. (2019). What if discipline is not interdisciplinary: The case of social psychology in India. Integrative Psychological \& Behavioural Science. https://doi.org/10.1007/s12124-019-9473-y

Smith, J. R., \& Haslam, S. A. (2012). Social psychology: Revisiting the classic studies. London: Sage.

Sugarman, J. (2015). Neoliberalism and psychological ethics. Journal of Theoretical and Philosophical Psychology, 35 (2), 103-116.

Sussman, R., \& Gifford, R. (2018). Causality in the Theory of Planned Behavior. Personality and Social Psychology Bulletin.

Świątkowski, W., \& Dompnier, B. (2017). Replicability crisis in social psychology: Looking at the past to find new pathways for the future. International Review of Social Psychology, 30(1). Article ID 111-124.

Taguchi, H. L. (2012). A diffractive and Deleuzian approach to analysing interview data. Feminist Theory, 13 (3), 265-281.

Tajfel, H. (1969). The formation of national attitudes: A social psychological perspective. In M. Sheriff (ed.), Interdisciplinary relationships in the social science (pp. 137178). Chicago: Aldine.

Tajfel, H., \& Turner, J. C. (1979). An integrative theory of intergroup conflict. In W. G. Austin, \& S. Worchel (Eds.), The social psychology of intergroup relations. Monterey, CA: Brooks-Cole.

Tanweer, A., Fiore-Gartland, B., \& Aragon, C. (2016). Impediment to insight to innovation: Understanding data assemblages through the breakdown-repair process. Information, Communication \& Society 19, 736-752.

Trafimow, D., \& Earp, B. D. (2016). Badly specified theories are not responsible for the replication crisis in social psychology: Comment on Klein. Theory \& Psychology, 26(4), 540-548.

Weick, K. E., Sutcliffe, K. M., \& Obstfeld, D. (2005). Organizing and the process of sensemaking. Organization Science, 16 (4), 327-451.

Weinberg, S. (2001b). Peace at last? In J. A. Labinger \& H. Collins (Eds.), The one ad-tare: A conversation about science (pp. 238-240). Chicago: University of Chicago Press. 
Data, Reality and Interdisciplinary Social Psychology

Wexler, P. (1983). Critical social psychology. Boston: Routledge \& Kegan Paul

White, P. (1990). Ideas about causation in philosophy and psychology. Psychological Bulletin, 108 (1), 3-18.

White, P. (1993). Psychological metaphysics. London: Routledge.

Wittgenstein, L. (1958). Philosophical Investigations. Oxford: Blackwell.

Woodward, J. (2011). Data and Phenomenon: a restatement and defense. Synthese, 182, 165-179.

Zachar, P (2014). A metaphysics of psychopathology. London: The MIT Press.

Zachar, P. (2014). The metaphysics of psychopathology. Cambridge: The MIT Press. 